\title{
Neurointerfaces as means of Artistic Research or Expanded Game Art
}

Margarete Jahrmann

'Play, radically broken from a confined ludic time and space, must invade the whole of life.

(...) play: the common creation of selected ludic ambiances. The central distinction that must be transcended is that established between play and ordinary life.' (Debord 1958)

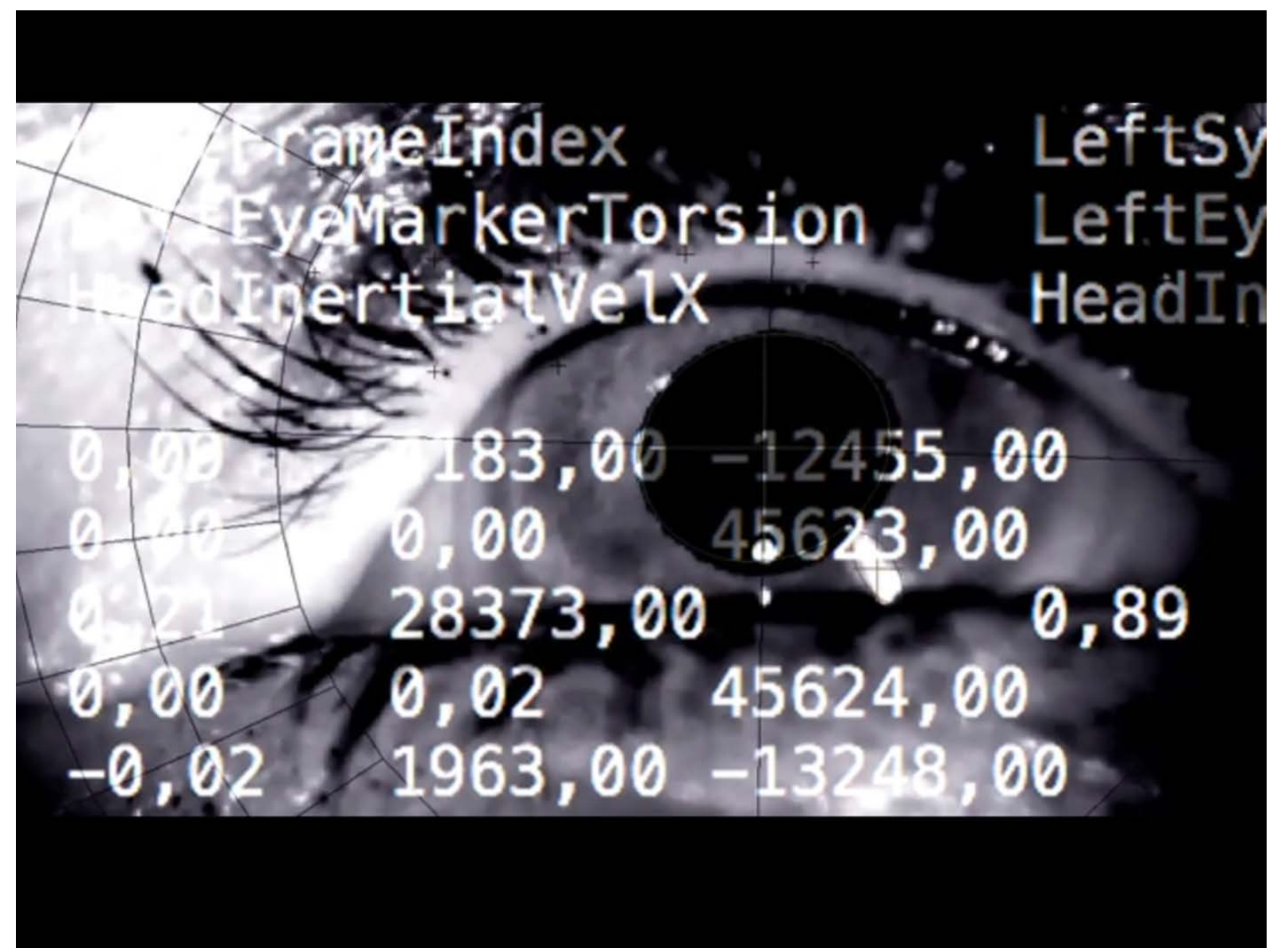

Image: Eyeseecam Neuroscientific Introspection, Margarete Jahrmann 2017

The practice of play as a form of political activism was introduced in the movement of Situationism (Debord and Wolman 1956). In the film and text 'La Societé du Spectacle' by Guy Debord (1958) found footage mass media materials and political messages were playfully merged as activist sub texts. Debord referred to this structural coupling as détournement, which he identified as practice of political activism. In current media art, this practical détournement of hard- and software in relation to the body can be found in game art. Reasons can be seen in in the rise of mobile communication devices and biometric interfaces with game like user interfaces. The fusion of technologies 
like augmented reality and everyday life biometric and brain interfaces with social requests for self-optimisation seems essential in our present society (Chevalier and Kiefer 2018). This industrially and scientifically introduced urge for a quantified self finds its anchor point in the expansion of playful media use into the inner self through consumer devices. Its corresponding interfaces are wrist bands containing gyro sensors for movement detection and brain-devices, that use simple versions of electroencephalogram (also abbreviated EEG) measurement, which is a standard examination method in neurology to record electrical activity of the brain. At this critical point of presence of such playful devices of record and control, a critical discourse on the ethical dimensions of such technologies and interfaces used in the sciences in relation to the recording of brain data in everyday life with mobile devices is necessary. The new consumer gadgets take our actual personal conditions into account. Information gained through neuro-interfaces is hardly questioned except in an emerging critical art form of neuro-games.

Promises of relaxation and life improvement are made by the end user market devices promotion with poetically promising names such as Emotiv (Shi et al. 2018). The central theme around the rise of such interfaces are its gamified use. In a playful participatory practice, personal data is collected. In the centre of the following inquiry stand this very actual forms of life science devices as individual toys in a mode of prosumption (Bruns 2007). The term prosumption is a portmanteau of the terms production and consumption and finds correspondence in the technological features of augmentation in a mixed reality, where the physical world and digital elements converge. In augmented reality games, codes call up digital information, which is usually displayed on everyday mobile technologies as smart phones or tablets (Toffler 1980). The very latest addition to this already established techno sphere of mobile devices and play worlds are biometrical interfaces (Zalasiewicz et al. 2016). Such interfaces like wristbands, smart watches and sensors are embedded in or extensions to the mobile gadgetry and ubiquitous computing devices of everyday use. The most spectacular kind of such interfaces are those that claim to measure the states of our very inner selves: brain interfaces.

\section{Expanded Game Art: Participative play as epistemic strategy about the inner self}


Game art evolved and was triggered to emerge through the appearance of engine editors almost two decades ago as sub-genre of media arts. Game art was introduced with the democratization of editing tools, wherein activist and critical statements were directed towards technology in general as a regulating system.

Game studies identified games as the art form of the $21^{\text {st }}$ century (Jenkins 2004)). However, it is an age where we constantly play with our mobile devices in a 'Ludic Society'. Just now, with the social online scoring of life, game art continues to grow in importance as vehicle of critical reflection of technologies. In its present form of philosophical commentary on the human condition, game art is ideally suited to embrace the hybrid and Situationist principle of political agency with game mechanics and public performances. Its focus is the body when dealing with everyday life technology (Leeker et al 2016). In a new genre of expanded game art, the rules of play converge with life science experiments.

\section{Participative play art, the body as interface}

Around 1968 artists already opened up a field of transgressing borders of the body as interface. Provocative body plays were seen in the early art of the female activist artist Valie Export. In her revolutionary Tapp und Tast Kino (1968/69), roughly translated as tap and touch cinema, the artist provocatively introduced a participatory momentum to the art work, when she invited passers-by on a street to touch her breast in a box mounted in front of her body, and claimed this action to be 'expanded cinema'. The element of play as revolutionary aspect is most evident in this work - but also the female emancipation by letting others play with her body according to her own rules. The labelling of the work as expanded cinema conceptually exceeds technological boundaries. The interaction mechanics of letting touch her breast in public space for a certain fixed time slot, decided by the artist, questions society norms, but also can be identified as clear game mechanics and the creation of a classical game rule in a magic circle of activist game art. 


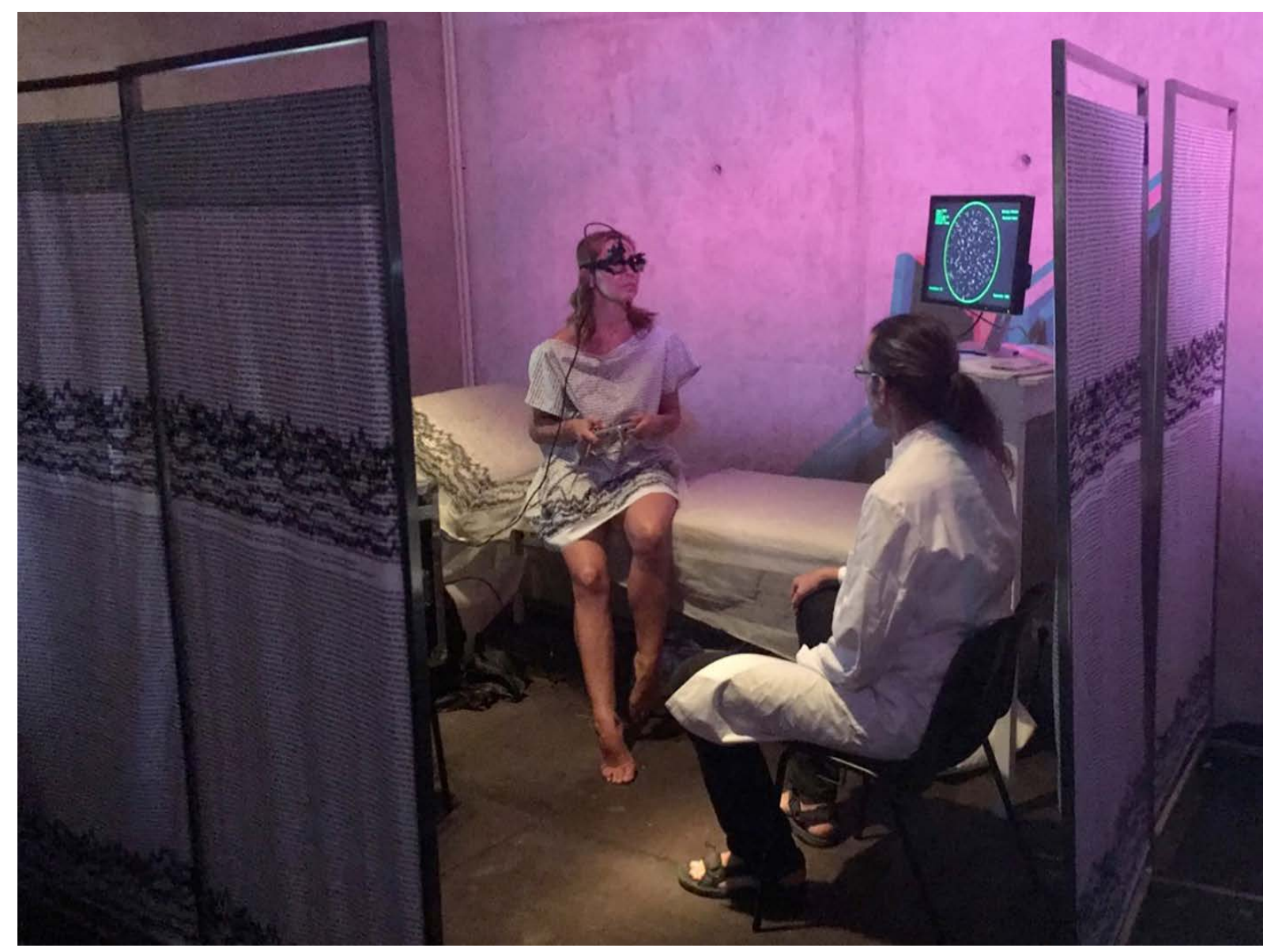

Image: Decision Demon Experiment, 2016 by Jahrmann\& Glasauer at the occasion of Opera of Entropy, Vienna.

A similar expanded game art provocation about using the body as personal data source in a public performance in a clearly defined set of play rules in public space is given in the work Decision Demon (2016). This performance and game art combination was developed by the neuroscientist Stefan Glasauer from the LMU Munich and me. As part of the performance a game with an embedded behavioural scientific experiment about decision making was provided to the audience, its neuroscientific content and the game art's take on a scientific experiment as a set of rules was explained to the players. The live experiment was publicly exhibited as game performance. In technical terms the installation combined a specially developed neuroscientific eyetracker goggle and a custom-made game as core of the expanded game art piece on visual perception (Stoll et al. 2011, p. 616-22). The used EyeSeeCam is a mobile eye-tracking device, developed by a team of neuroscientists in Germany, whose camera-motion device (gazecam) records movies of the user's direction of gaze. This gaze-tracking device is used in standardized clinical settings. As the developers state, mobile eyetracking is a recent method enabling research on attention during real-life 
behaviour. The situation of the Decision Demon experiment could meet a request of natural behaviour observation, as it was performed in the context of the Opera of Entropy (a project by the artists Jelinek and Sanchez, 2016-2018) in a public setting of random visitors ${ }^{1}$. The piece's essence was the exposure of the body of the performer as test subject and the seduction of the visitors through the means of gaming to do the same. The provided invitation to play was used as excuse to display personal data publicly - and to allow to make the experience of how biometric data can be taken and interpreted. Each player performed in the installation and turned into a prosumer. In that sense a game art setting in a public installation can fruitfully contribute to the sciences with the advantage of a controllable set of rules, which is useful for the research validity. On the other hand, biometric aspects and neuro-interfaces used in a performative installation allow to design a new kind of game art, made of elements of behavioural research and a critical questioning of the interfaces used in play.

The argument made using the example above follows the hypothesis that participatory principles also can be found inherently in science, arts, and games, which is newly fostered through the convergence of the technological framework of games and neuro-interfaces. Everyday processes of self-measurement for health improvement and self-optimization take place in a multi-layered world of play, games and gadgets. The augmented virtual worlds in health apps are gamifying life routines, from eating over walking to sleeping - far beyond oversimplified gamification principles. ${ }^{2}$ The periphrasis of gamification implies that play is key to be used in other context than games for the creation of something. Play often serves as invitation to share experiences, like in health and fitness apps. But playful participatory practices are introduced as ideal to be followed to contemporary socially networked society by economic and marketing considerations. They are based on a capitalist understanding of the self as personalized object, as good, socially capitalized through scoring in publicly shared networks. With the rise of social network platforms, a new imperative arose in our

\footnotetext{
${ }^{1}$ Equally a scientific interest was met, as the installation appeared as more natural environment than a laboratory setting. Such closeness to real life is an aim to life science research. The public performance provided a more natural test situation - while the game mechanic still allowed to create a controlled environment.

${ }^{2}$ For a general introduction to the concepts of gamification see McGonigal (2011). For a critical re-examination and reflection of gamification see the volume Rethinking Gamification by Mathias Fuchs, Sonia Fizek, Paolo Ruffino and Niklas Schrape (2014). For a critique of gamification using Geertz's concept of Deep Play see Jahrmann (2018).
} 
present networked society: the one of participation - the participative imperative, as I would like to coin it here. It is crucial to recognize herein a new form of playful produsage: the final product is the healthy and better self. In an act of resistance, this approach of capitalizing the inner self as product has to be critically considered. Principles of activism developed in over a decade of game art must now be applied.

\section{Citizen Science Games: Playful participatory research}

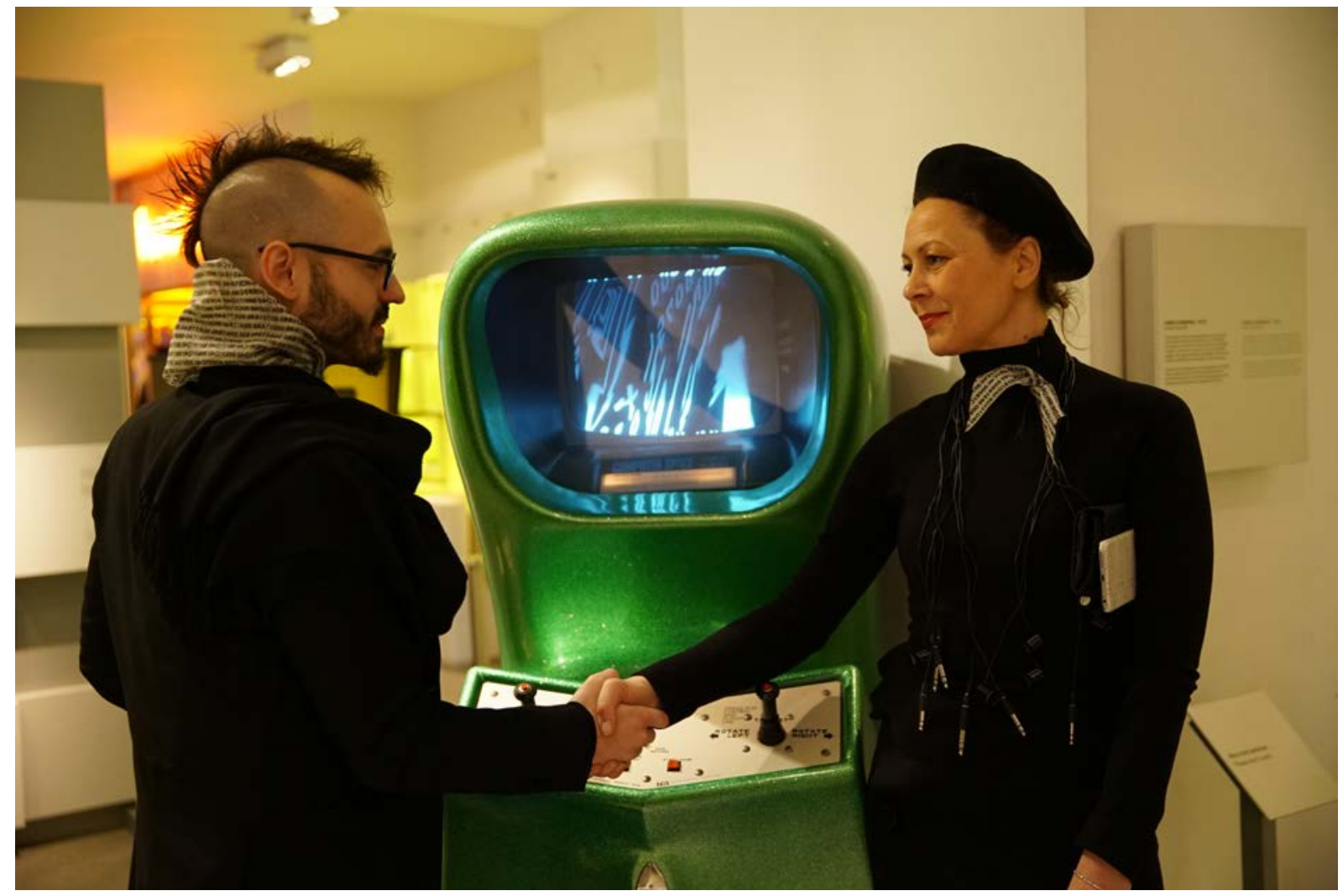

Image: Neuroflow on Computerspace Console, Jahrmann\& Wagensommerer, 2018 Berlin

Game systems are also increasingly used to contribute to the analysis of scientific data, like in the project Decodoku (2016) by James Wootton from the University of Basel (Wotton 2016). The scientist translated his research into a game, his Decodoku resembles Sudoku. The problems built into the game are very difficult for computers to solve but considerably easier for humans. With the help of the game the researcher aims to find out why this is the case. The data gained about processes of problem solving contributes to a better understanding of possible quantum solutions in computing. In this highly interdisciplinary field about our human perception and cognition a fruitful and promising exchange between art and sciences emerges. This is especially valid when the behaviour of the user is fed back 
into the system - so the research game does not only display research outcome but also generates further research data. Such games can be seen as new tendency of artistic research.

On the other hand, Augmented reality games in research can also serve as source for gaining data. Principles of play and produsage applied in research can turn the situation of consuming research material and findings into a pro-active situation of experiencing game art installations as integral part of research.

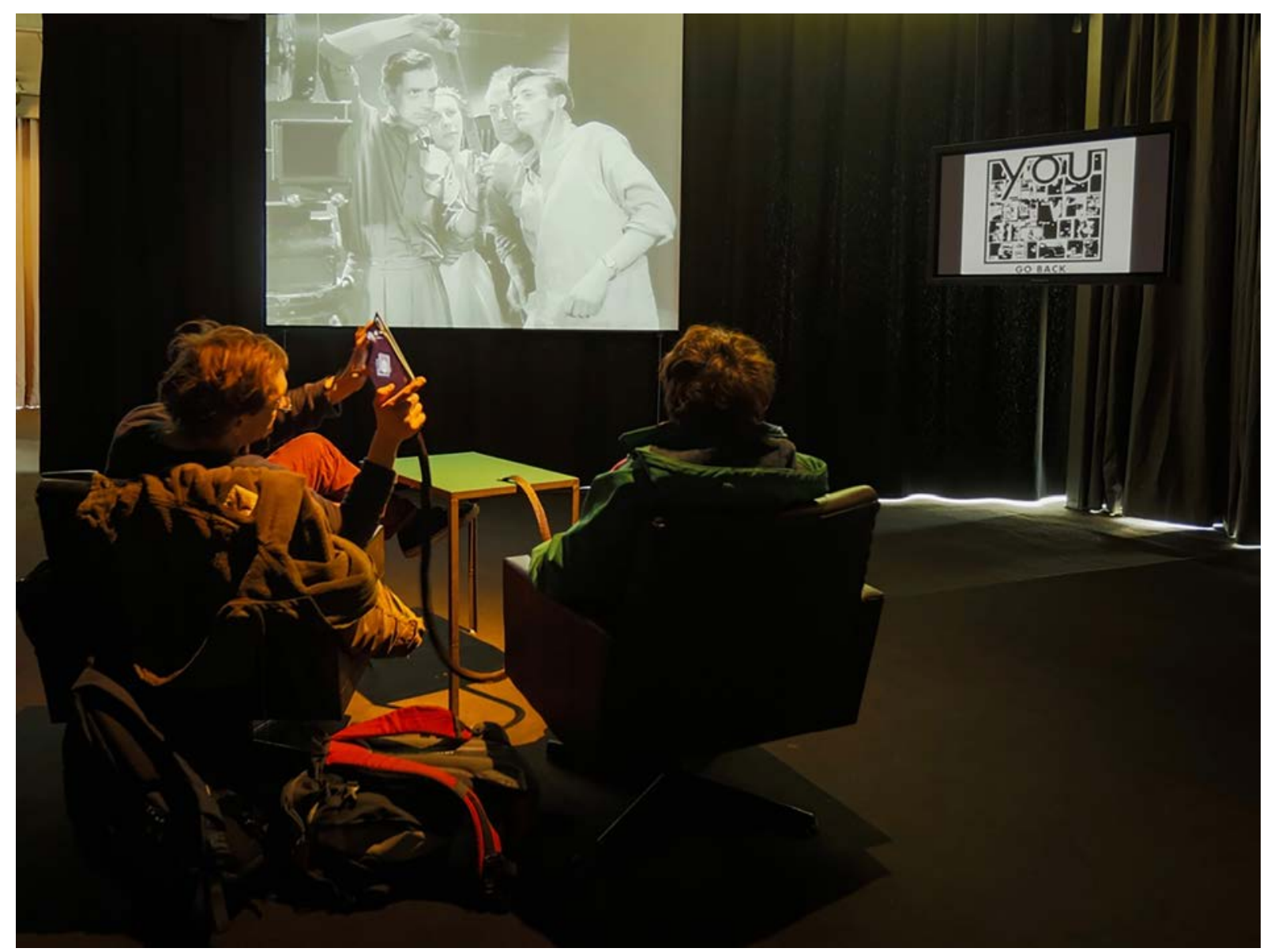

Image: Play and Prosume Augmented Reality Exhibition, 2013, Kunsthalle Vienna.

Play as an artistic research practice can be very clearly defined when games are part of public exhibitions. An exemplary research project on such an exhibition game, where data was collected as in present citizen science games was Play \& Prosume at Kunsthalle Vienna (2013). A playful media arts installation allowed to look in depth how the process of exchange between art and research was established. Colleagues of the international team used the data for their following academic research projects. The role of the researchers was 
to actively contribute to the game design. The Play \& Prosume game took the shape of a major participatory augmented reality exhibition game with multiple layers:

1. The game was played with mobile tablets and an Alternate Reality App in the exhibition. Specially designed textile patterns were trained as codes of software. These codes were used as triggers in the game play.

2. The interplay between art, technology and research was specifically staged in the exhibition architecture as game layout. Research contents were not only presented and exhibited, but the exhibition itself was a tool for the research team. It was a test facility in which technology was a vehicle to obtain data about the visitors.

3. The exhibition game was a data source for the research project Technology, Exchange and Flow: Artistic Media Practices \& Commerical Application undertaken under the European framework of HERA, Humanities in the European Research Area. ${ }^{3}$ The project explored the relationships between creativity and innovation. As such it was intended to prepare the way for thinking about new media environments when the distinctions between the consumer and the producer are no longer valid or viable.

4. Various works of art were generated as commissioned works for the exhibition game stage: Artistic films were cut with certain key motifs from research on the project theme. Performances were specially designed for the exhibition, such as the first television broadcasting in history to be re-enacted as an event at the exhibition opening.

Collective game mechanics were used in order to involve the audience into a process of playful produsage - with the objective to reflect on the contemporary urge to contribute equally to commercial production of goods and knowledge. The design of the exhibition game aimed at demonstrating mechanisms of control in technologies and to show how the human desire to creatively play is exploited in common participatory offers of social networks and games. A process of insight about relations and implications of networked technologies and games was achieved by turning the visitor of an exhibition into a prosumer who co-creates an exhibition through means of play.

The act of looking and peeking transgressed the apparatus of controlled research of media perception and put the visitor into an activated position. The most important point here was to unconsciously trigger participation instead of requiring a conscious action, especially because the codes were integrated into the environment. The graphic and design of visual

\footnotetext{
${ }^{3}$ http://heranet.info/projects/hera-2009-humanities-as-a-source-of-creativity-and-innovation/technologyexchange-and-flow-artistic-media-practices-commerical-application/
} 
marker codes influences insights about subliminal messages and produsage, analysed in research. The exchange and dissolution of walls between the academic and artistic paradigm can be expressed through a technological multi-layer conception of an Augmented Reality $(A R)$ and citizen science games. The AR technology allows to access research materials and its related findings. But most importantly it also traces user behaviour, collects data about decisions made and ways chosen throughout the given content. This makes clear, how digital consumption is inseparable from the production of new data.

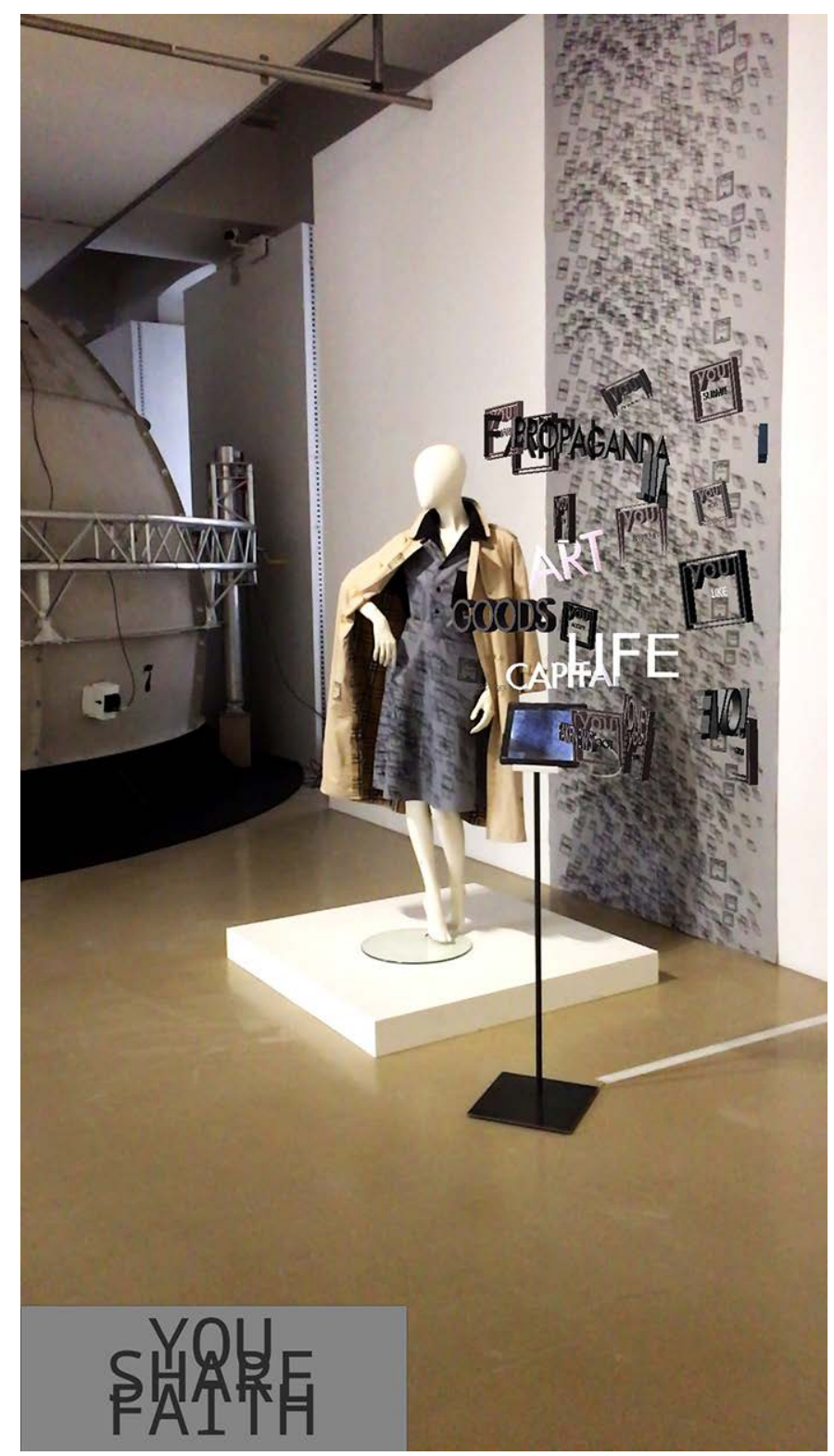

Image: Subliminal Message Game, Augmented Reality Game 2018, Kunstraum Palais Niederösterreich, Vienna. 
The whole concept of the Play\& Prosume exhibition game profited from other art pieces developed around the research team, like the AAA profiler. ${ }^{4}$ During attended times, visitors were guided by a hostess, which herself was dressed in cloth covered with AR codes. The hostess invited visitors to a 'photo shooting'. Using the mobile phone to look at the exhibition space, covered with artfully designed AR codes, an augmented layer unfolds.

The App was provided in the Appstore. Once it was installed, photos taken of the AR codes in the exhibition site called up Twitter messages and combined and retweeted them with new absurd sentences. In a Situationist cutting up content of mass media was re-used in order to reflect on the manipulative function of participatory playful practices.

The installation was a critical analysis of a leading orientation of modern societies towards mobile electronic interfaces, which are increasingly connected to game-like social networks. A new version of this war was exhibited in the Palais Niederösterreich in Vienna under the title Subliminal Message Game in 2018. Now the project unfolds as game, that allows to combine new sentences and share them as hybrid message of a photo, selfie and statement.

Such contemporary forms of game art aim to foster discourse on the human body and data protection, techno-philosophy and activism. The importance of this field for the society in general can be identified according to evidences in the use of particular biometrical interfaces and technologies of hybrid forms of alternate realities, that affect real life. Seen from this angle we can contextualize citizen science games and expanded game art as new genre. In present society, games in convergence with personal data have become comprehensive media that concern human existence in its innermost physicality. Conversely, game art has reached a stage in which, building on a broadly supported culture of reflection, both forms of expression and creation of meaning can be claimed in a new field of artistic research. For example, the use of computer games as simulation space seem to be useful for experiments with human and non-human primates when it comes to the design of clearly controllable systems and the generation of clearly evaluable data. In 2017 at a research visit at the Washington Primate Research Center in Seattle I could see non-human gamers in the

\footnotetext{
${ }^{4}$ The AAA Profiler installation introduces new AR codes to call up hidden messages, apply Cut-Up methods on Twitter feeds, recombines them with images, which can be taken anywhere in the world. It broadcasts a new combination of images, tweet fragments and hidden messages as new Twitter messages of the day and shows them live in the Muqua installation and webstream. This hybrid reality installation was developed by Margarete Jahrmann with Brigitte Felderer, Fares Kayali and Josef Schuh, http://ludic.priv.at/AAA/AAA Profiler/a.html.
} 
laboratory. Games these primates are playing enable research into our brain functions and dysfunctions.

\section{Neuro Games: Participative play in research}

Brain controlled games and an emerging field of brain interfaces to control games appear in reciprocal use in the field of game design. An entry of brain wave analysis into the field of art through game performance is central to an advanced understanding of how science and art can intertwine to produce new forms of experience and aesthetic critique in its original meaning of aisthesis as perception.

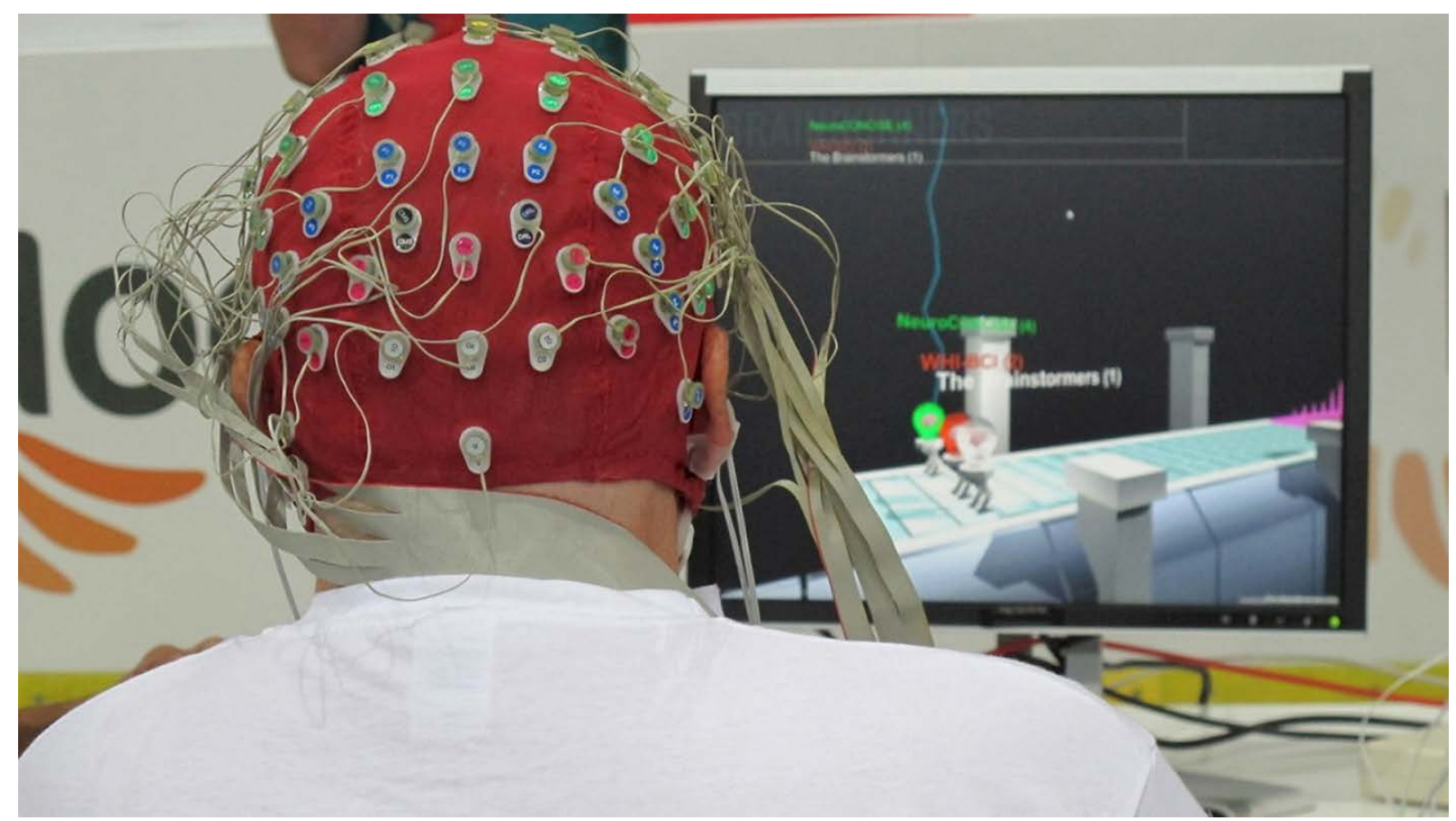

Image: Brainrunners (2016), ETHZ and ZHDK Zürich

The lead developer of Brainrunners (2016), the swiss game designer and artists René Bauer, sees the brain computer interfaces used in games as very radical version of e-sports. The interface is directly embedded into the player subject. In that sense the interface almost disappeared and allows to directly control elements of a game. The Brainrunner race simulates the control of future support devices, that support and improve the life quality of disabled persons. Here brain computer interfaces have to prove themselves in reliability and precision. For this purpose, the virtual Derby game Brainrunners was developed in 2016 on the occasion of a Cybathlon organized by the ETH Zurich as cooperation of the ETHZ Sensory- 
Motor Systems Lab and the Zurich University of the Arts Game Design department. ${ }^{5}$ At the Cybathlon, people with severe physical disabilities competed against each other. The basis of the game mechanics in Brainrunners is the difference of signals received from test subjects in states of concentration and relaxation. Each of this states either moves or stops a game figure -which is displayed as a running character in the game design. The resulting race was performed in the spectacular public event Cybathlon at a big sports stadium in Zurich. However, the interpretation of the brain data has nothing to do with thought control, which is falsely often mentioned in relation to brain interfaces, only with the addressing of a device through body data gained. Those brain devices use electroencephalography (EEG) to measure and interpret functional brain impulses for game control allow a completely new intuitive play with the machine and a social produsage system.

As games are increasingly considered as vehicle for self-optimization, the gamification of everyday life becomes a status quo in the interaction with technological interfaces. The hardware devices in self measurement (health wristbands, mobile devices, smart watches and heart rate analysis) are a new wave of human computer interfaces, that intrude the body in a more direct way for the collection of personal data. As this appears as most relevant question in a society, art is the ideal vehicle to address it. Game art as a genre of critical media arts is ideally suited for providing a platform for investigating the possible role and relevance of neuro-interfaces for society and politics. In artistic research a new form of neuro games elevates. A new expressive art form based on the critical inversion of brain interfaces emerges from an approach that embraces neuro-devices and game mechanics and communicate its potential for the society. Then in this particular kind of game art neurointerfaces become a participative and creative technical tool that allows insight into brain functions and monitoring while at the same time can be used as creative output device. 


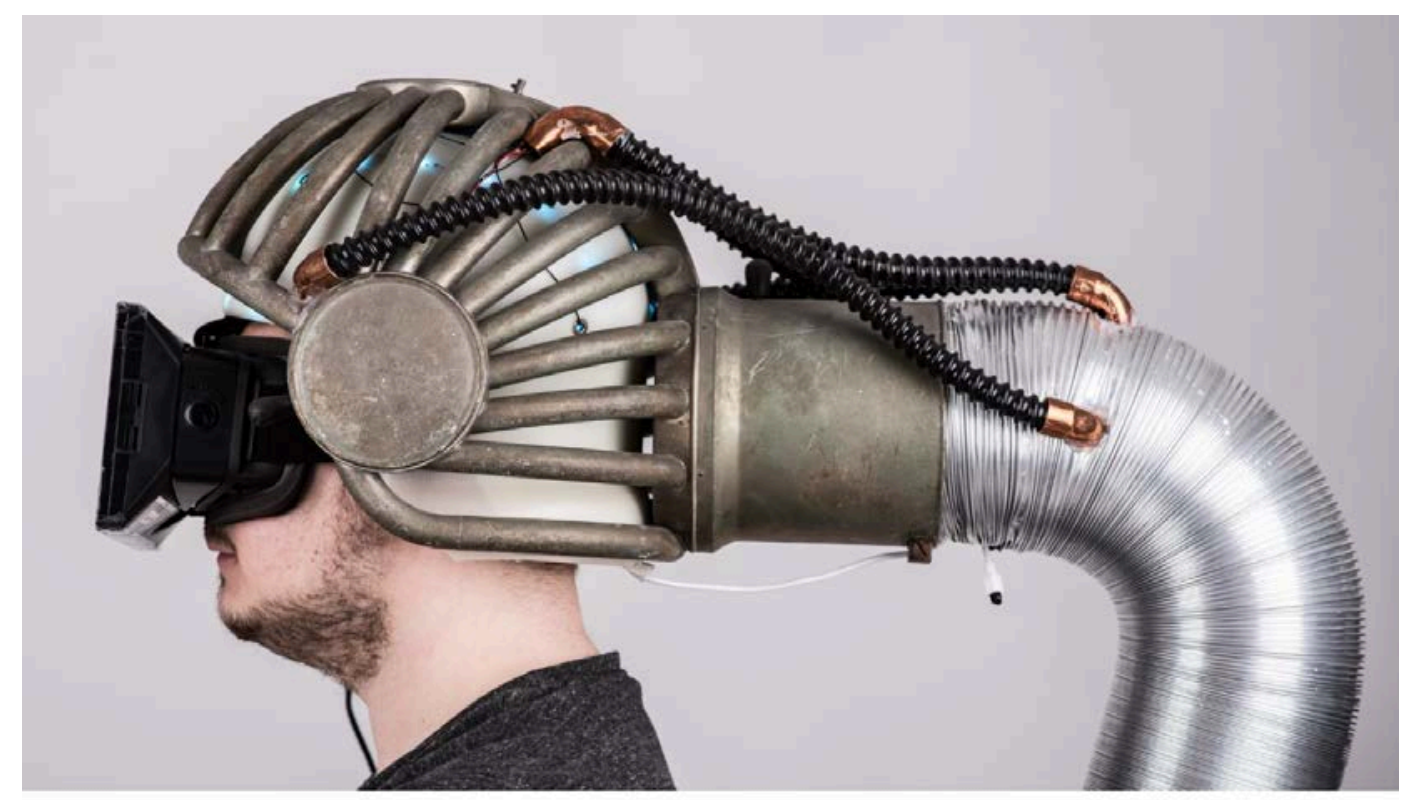

Figure 45 - Conceptual Physical Prototype of the BCl-VR Helmet

Image:

image: Steampunk Neurointerface, Jens M Stober 2013/2017

The artistic and experimental Neuro-VR Game RIDE YOUR MIND by Jens M. Stober, (2013/2017), makes use of neurofeedback to calculate the stress or relaxation level of its player. The conceptual gameplay involves several elements that are related to the player's stress or relaxation levels. Stober introduces an artistic response to the technological and design questions caused by emerging technologies of biofeedback games and virtual reality in his art piece. RIDE YOUR MIND playfully explores, examines and hacks the possibilities of consumer brain-computer interfacing technology. The game combines neurofeedback with virtual reality and makes use of consumer grade brain-computer interfacing technology. A EEG headset is combined with an Oculus Rift Head Mounted Display. The project highlights the possibilities of designing a game with existing consumer neuro-interfaces in a quite unique way. As an object, comparable to a fictional bio adapter, the piece holds a potential to be further placed in the arts discourse and market. In that aspect, the piece contributes significantly to a new way of understanding new consumer items in the neuro-game field. The art work is informed by affective games as future field of game design. Game art informed by neuroscientific research and philosophical discourse works test limits of neurointerfaces as everyday tools of scientific relevance. Play principles can be found in each interface technology as well as in the most serious experimental systems of life science research. In professional and consumer interfaces motivation for the use is oftentimes spurred on by gamification. 


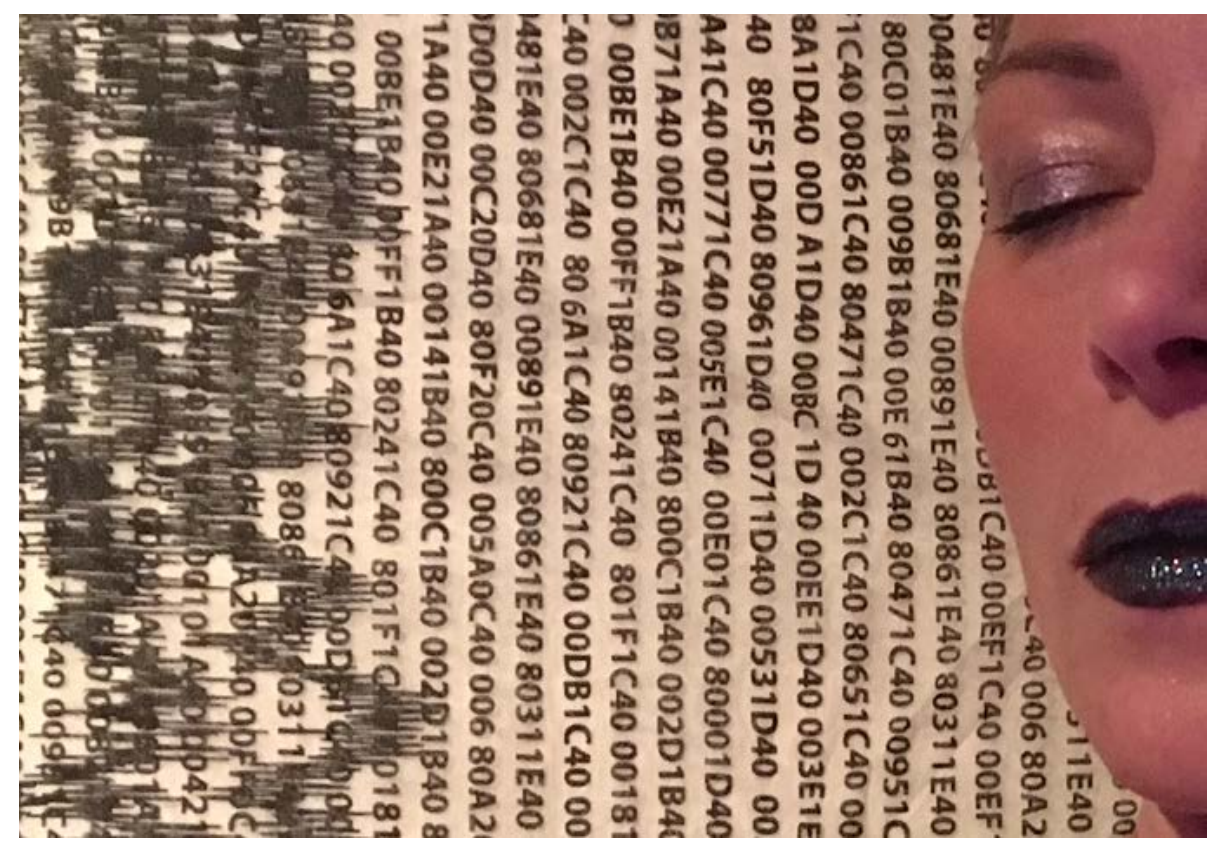

Image: Neuroflow Game (2018), Margarete Jahrmann/Thomas Wagensommerer, Amaze Festival Berlin.

In the NEUROFLOW Game (2018) motivation design is led to the absurd by a game that cannot be controlled. ${ }^{6}$ The Neuroflow Game was premiered at Amaze Festival for Playful Media, Berlin. The game mission was to reach a state of meditative flow and to play with user expectation of mind control in present consumer devices taking biometrical data - for the sake of new form of produsage, where the very private and inner data of body functions is left for commercialisation.

The use of a neuro-interface serves as motivation for a secure test of such a device in a game. The aim of the game is to achieve a state of flow. Flow is defined by the psychologist Mihaly Csikszentmihalyi as an altered state of mind, wherein we achieve happiness through intrinsic motivation (Csikszentmihalyi 1991). The achievement of flow is applied in this game as a more sensible mode of perception and interaction, that allows a deeper insight into the functions of mental processes. It tests how far control can be taken, to elucidate new ways of perception of the world through a critical use of neuro-interfaces. In this art pieces' game design the superstitious element of brain reading is exploited and the effect of play experience intends to let a resistance of the test subject grow. Private biometrical data is increasingly capitalized in the market of neuro interfaces for everyday use and health gadget measuring EEG data connected to mobile phones. This is what the Neuroflow game aims to

${ }^{6}$ http://www.neuroflow.games 
transport as activist message, going beyond the pure experimentation of the usability of neuro interfaces. A critical questioning of the brain computer interface as such is required due to the increasing urgency of more and more present devices of body measurement and self-optimization in everyday life. The ethical dimension of the use of neuro interfaces is hardly questioned, neither in research nor in its artistic applications, which is surprising but a necessity for the self-determined user who is more than an object of produsage.

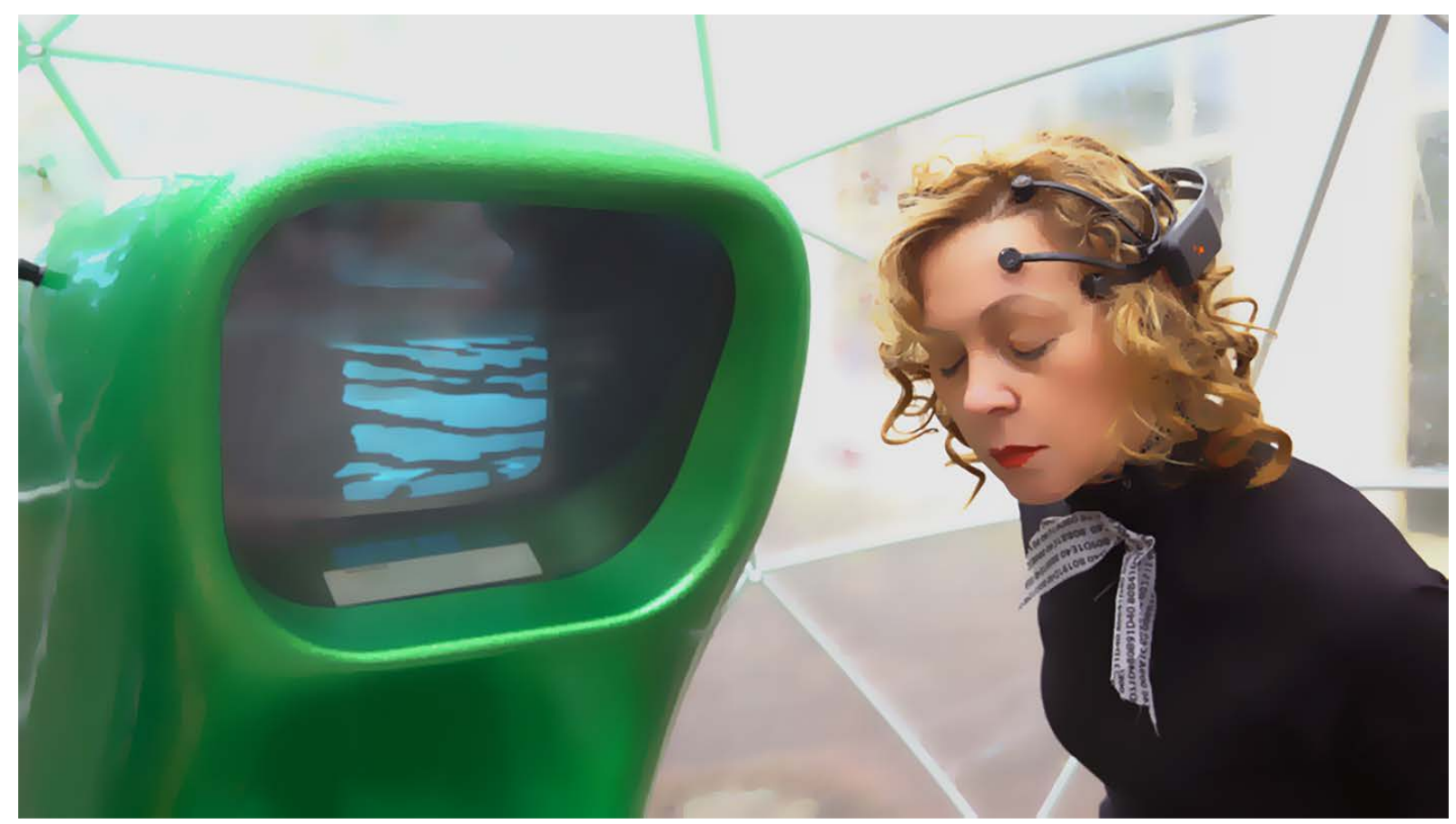

Image: Neurospace Game, performing and meditating in front of the Computerspace Console, 2017 Berlin

Nevertheless, the situation of a publicly performed experiment is often seen in arts contexts. Core to the performance game Neurospace! (2017) was the staging of an experiment in public space. ${ }^{7}$ The game embraces a live-action roleplay with neuroscientists and game designers, brain-states, neuro-interfaces and the re-use of the iconic Computerspace Console from 1971. The object was provided out of the collection of Computerspielemuseum Berlin. At the occasion of its anniversary this museum was opening its doors for game art of a new kind, connecting the very historic game console artefact with the very newest form of brain interfaces. The console now appeared as emanation of cold war infused with new humanism.

\footnotetext{
${ }^{7}$ http://neuro-space.net
} 
The inner space of brain signals is represented in the retro-futuristic brain game Neurospace!. The work was commissioned by and performed at the Computerspielemuseum Berlin. It took the form of a public neuroscientific experiment played on a historic game console, Space Invaders from 1972. The title Neurospace! was coined as a reference to the early computer game Spacewar! (1962) which was first presented to the public at the annual MIT's Science Open House - in a kind of public performance. The display of the computer game was a green screen oscilloscope, which normally displayed signals of radar data and then was also used as input device with a light pen on the computer system PDP1 (Programmed Data Processor-1). The green screen of the game also represents the navigational screen of the Spacewar! program, the circular radar screen controlled with the light gun, waiting for potential fire commands.

As conclusion, the mentioned citizen science and expanded game art pieces successfully communicate a sustained argument on the vibrancy of neuro-interfaces in its social and political dimension of the very actual form of biometrically induced produsage.

The illusion of being in control of a game is fundamentally questioned in games with neurointerfaces. Artistic experiments involving games as strategies of participative research aim at contemporary technologies of brain scanning and analysis, e.g. through experimenting with the effects of meditation practices and forms of introspection into machines that function solely on mathematical modelling. A perceived loss of control is an important issue in all brain computer Interface games - and is not an error but a feature. An approach of thematising the impossibility of control is actually the only viable way to deal with biometric produsage concepts.

Core to this emanating genre of research games is the involvement of a hybrid interplay of an inquiry of political questions around personal data. Playful principles allow a controlled shaping of an investigation in arts research as well as in sciences, which opens up three different fields of research:

First, a critical discourse of the ethical dimensions of technologies and interfaces used in sciences and increasingly everyday life self-optimizing is key to our contemporary societies. Second, the emerging mobile interfaces and consumer interfaces promise a new genre and research field in game design, wherein game arts can find its own future profile. Third, a 
controlled game environment in its form as expanded game art includes hybrid spaces between interfaces, technologies and the body. They fulfil the scientific requests for a more naturalistic approach in experimental sciences. This can contribute to the science and epistemic object beyond artificial laboratory situations.

\section{References}

Ahn, Luis von. 2006. Games With A Purpose. In IEEE Computer Magazine: 96 -98.

Ahn, M., M. Lee, J. Choi, and SC. Jun. 2014. A Review of Brain-Computer Interface Games and an Opinion Survey from Researchers, Developers and Users. In Sensors, 14(8): 1460114633.

Bruns, Axel. 2007. Produsage: Towards a Broader Framework for User-Led Content Creation. In Proceedings Creativity \& Cognition 6, Washington, DC.

Bruns, Axel. 2008. The Future Is User-Led: The Path towards Widespread Produsage. In Fibreculture Journal (11). Page (?)

Chevalier, Cecile and Chris Kiefer. 2018. What does augmented reality mean as a medium of expression for computational artists? In Leonardo Journal.

Csikszentmihalyi, Mihal. 1990. Flow: The Psychology of Optimal Experience, New York: Harper Perennial.

Debord, Guy, and Gils Wolman. 1956. Mode d'emploi du détournement. In Les Lèvres Nues. Paris.

Fuchs, Mathias, Sonia Fizek, Paolo Ruffino, and Niklas Schrape. 2014. Rethinking gamification. Lueneburg: Meson Press.

Jahrmann, Margarete. 2018. Constant beyond Gamification. Deep Play in Political Activism. In: Playful Disruption of Digital Media, Ed. D. Cermak-Sassenrath, 193-213. New York: Springer Nature.

Jahrmann, Margarete and Brigitte Felderer. 2013. Play \& Prosume. Schleichender Kommerz und Schnelle Avantgarde. Nürnberg: Verlag Moderne Kunst. 
Jenkins, Henry. 2006. Convergence Culture: Where Old and New Media Collide. New York: University Press.

Leeker, Manuela, Immanuel Schipper, and M. Beyer, Eds. 2016. Performing the Digital. Bielefeld: transcript.

Lutters, Bart and Peter Koehler. 2016. Brainwaves in concert: the 20th century sonification of the electroencephalogram. Brain. doi: 10.1093/brain/aww207.

McGonigal, Jane. 2011. Reality Is Broken: Why Games Make Us Better and How They Can Change the World. New York: Penguin Books.

Mitra, Sinjini and Mikhail Gofman. 2016. Biometrics in a Data Driven World: Trends, Technologies, and Challenges. Boca Raton: CRC Press.

Mladenović, Jelena et al. 2017. The Impact of Flow in an EEG-based Brain Computer Interface. In Proceedings of the 7th International BCl Conference, Graz. https://www.tugraz.at/institute/ine/graz-bci-conferences/graz-bci-conference-2017

Shi, M., X. Liu, and C. Zhou, et.al. 2018. Towards portable SSVEP-based brain-computer interface using Emotiv EPOC and mobile phone. In Tenth International Conference on Advanced Computational Intelligence (ICACI), Xiamen.

Sommerer, Christa, Ulrich Brandstätter, and Laurent Mignonneau. 2015. Interface-Centric Art Games. In Handbook of Digital Games and Entertainment Technologies. 1-28. Singapore: Springer Singapore.

Stober, Jens. 2013. Ride Your Mind. In Context matters! Proceedings of the Vienna Games Conference 2013: exploring and reframing games and play in context. Vienna: New Academic Press. Pages (?)

Stoll, J., S. Kohlbecher, S. Marx, E. Schneider, and W. Einhäuser. 2011. Mobile three dimensional gaze tracking. In Stud Health Technol Inform 163: 616-22.

Tan, Desney S., and Anton Nijholt. 2010. Brain-Computer Interfaces. In Brain-Computer Interfaces - Applying Our Minds to Human-Computer Interfaces, Ed. Desney S. Tan and Anton Nijholt, 3-19. London: Springer London. 
TEF 2010, Technology, Exchange and Flow: Artistic Media Practices and Commercial Application.

http://trans-techresearch.net/tef/. Accessed: 2 January 2011.

Toffler, Alvin. 1980. The Third Wave. New York: Bantam Books.

Wootton, James. (2016). A Playful Approach to Quantum Computing. https://www.unibas.ch/en/News-Events/News/Uni-Research/A-playful-approach-toquantum-computing.html. Accessed:

Zalasiewicz, J. et al. 2016. Scale and diversity of the physical technosphere: A geological perspective. In The Anthropocene Review Vol. 4(I): 9-22. 